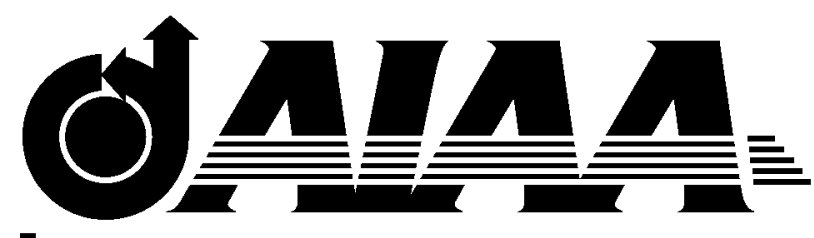

AIAA-2002-0420

Investigation of Transonic Reynolds Number Scaling on a Twin-Engine Transport (Invited)

M. M. Curtin, D. R. Bogue, and D. Om

Boeing Commercial Airplanes

Seattle, Washington

S. M. B. Rivers, O. C. Pendergraft, Jr., and R. A. Wahls

NASA Langley Research Center

Hampton, Virginia

40th AIAA Aerospace Sciences Meeting \& Exhibit

$$
\begin{gathered}
\text { 14-17 January } 2002 \\
\text { Reno, Nevada }
\end{gathered}
$$

For permission to copy or republish, contact the copyright owner on the first page. For AlAA-held copy-right, write to AIAA, Permissions Department, 1801 Alexander Bell Drive, Suite 500, Reston, VA 20191-4344 


\title{
Investigation of Transonic Reynolds Number Scaling on a Twin-Engine Transport (Invited)
}

\author{
M. M. Curtin ${ }^{\star}$, D. R. Bogue ${ }^{\dagger}$, and D.Om ${ }^{\ddagger}$ \\ Enabling Technology \& Research \\ Boeing Commercial Airplanes \\ Seattle, Washington \\ S. M. B. Rivers ${ }^{\star *}$, O. C. Pendergraft, Jr. ${ }^{\dagger \dagger}$, and .R. A. Wahls ${ }^{\ddagger \ddagger}$ \\ Aerodynamics, Aerothermodynamics, and Acoustics Competency \\ NASA Langley Research Center \\ Hampton, Virginia
}

\section{ABSTRACT}

This paper discusses Reynolds number scaling for aerodynamic parameters including force and wing pressure measurements. A full-span model of the Boeing 777 configuration was tested at transonic conditions in the National Transonic Facility (NTF) at Reynolds numbers (based on mean aerodynamic chord) from 3.0 to 40.0 million. Data was obtained for a tail-off configuration both with and without wing vortex generators and flap support fairings. The effects of aeroelastics were separated from Reynolds number effects by varying total pressure and temperature independently. Data from the NTF at flight Reynolds number are compared with flight data to establish the wind tunnel/flight correlation. The importance of high Reynolds number testing and the need for developing a process for transonic Reynolds number scaling is discussed. This paper also identifies issues that need to be worked for Boeing Commercial to continue to conduct future high Reynolds number testing in the NTF.

\footnotetext{
*Aerodynamics Engineer, High Speed Aerodynamics

†Aerodynamics Engineer, Stability and Control

‡Manager, Lines Definition and Flight Characteristics

**Aerospace Engineer, Configuration Aerodynamics Branch, Member, AIAA

t†Aerospace Engineer, Configuration Aerodynamics Branch, Senior Member, AIAA
}

¥łAssistant Head, Configuration Aerodynamics Branch, Associate Fellow, AIAA

Copyright (c) 2002 by the American Institute of Aeronautics and Astronautics, Inc. No copyright is asserted in the United States under Title 17, U. S. Code. The U. S. Government has a royalty-free license to exercise all rights under the copyright claimed herein for Governmental Purposes. All other rights are reserved by the copyright owner.

\section{INTRODUCTION}

The continued development of Reynolds number scaling methodologies to predict airplane flight characteristics remains an important task for aircraft design. The 777 program was the first Boeing program to use high Reynolds number testing during development (Ref. 1). Models were tested at the NASA Ames $11 \mathrm{ft}$ transonic wind tunnel to obtain Reynolds number effects in the 316 million range. These results were extrapolated to flight Reynolds number at cruise conditions in the 40-50 million range. Advancement of Reynolds number scaling processes for the complete flight envelope, including cruise, stability and control and loads design conditions will improve confidence in pre-flight predictions for future aircraft. High Reynolds number testing provides comparisons to improve computational fluid dynamics (CFD) or empirically based methodologies for scaling.

In 1997 Boeing and NASA Langley Research Center jointly developed plans to investigate Reynolds number scaling using the National Transonic Facility. The 777 was chosen as a study vehicle because of its high technology wing design and the large amount of wind tunnel and flight test data available for comparison. NASA Ames, NASA Langley and Boeing provided funding for building the model. The testing was done under a cooperative agreement between NASA Langley Research Center and Boeing.

This study includes an ongoing effort to evaluate the capabilities of CFD to predict Reynolds number trends. Analysis using Tranair, Overflow and TLNS3D-MB is being performed across the range of Reynolds number, Mach and angle-of-attack 
tested. The comparisons will be used to identify opportunities for improving CFD predictions for both level and trends of aerodynamic parameters.

This paper discusses some of the Reynolds number trends observed for the 777. These results build on the database that includes 767 and other transport models already tested at NTF (Refs. 2-5). Some results of CFD analyses completed to date are also presented.

\section{NOMENCLATURE}

\begin{tabular}{|c|c|}
\hline AR & Aspect Ratio \\
\hline $\mathrm{C}_{\mathrm{D}}$ & drag coefficient \\
\hline $\mathrm{C}_{\mathrm{Dp}}$ & $\begin{array}{l}\text { Idealized Profile drag coefficient } \\
C_{D}-C_{L}{ }^{2} /(\pi \times A R)\end{array}$ \\
\hline $\mathrm{C}_{1}$ & sectional lift coefficient \\
\hline $\mathrm{C}_{\mathrm{L}}$ & airplane lift coefficient \\
\hline $\mathrm{C}_{\mathrm{M}}$ & $\begin{array}{l}\text { pitching-moment coefficient referenced to } \\
0.25 \text { mac }\end{array}$ \\
\hline Cp & pressure coefficient \\
\hline$E$ & modulus of elasticity \\
\hline ESP & electronically scanned pressure \\
\hline M & Mach number \\
\hline $\operatorname{mac}$ & mean aerodynamic chord \\
\hline NTF & National Transonic Facility \\
\hline $\mathrm{P}_{\mathrm{T}}$ & total pressure \\
\hline q & dynamic pressure \\
\hline $\operatorname{Re}_{\mathrm{c}}$ & Reynolds number based on mac \\
\hline $\mathrm{x} / \mathrm{C}$ & non-dimensional chordwise position \\
\hline$\alpha$ & angle of attack \\
\hline$\eta$ & nondimensional semispan station \\
\hline$\theta$ & $\begin{array}{l}\text { sectional wing twist change, relative to } \\
\text { wind-off twist }\end{array}$ \\
\hline
\end{tabular}

\section{TEST OBJECTIVES}

This was one test in a series to assess and improve wind tunnel-to-flight extrapolation methods for aerodynamic characteristics at transonic conditions. The objective is to investigate the variations of global properties and wing sectional properties from Reynolds number typical of the Boeing Transonic and the NASA Ames $11 \mathrm{ft}$ Wind Tunnels to flight Reynolds number. The Mach and angle-of-attack range covers cruise, stability and control, and structural loads design conditions. The question "How much Reynolds number is enough?" will be addressed by adding to the database of Reynolds number effects for different wing technologies and configuration items, such as vortex generators. Also, CFD prediction of levels and trends with Reynolds number will be assessed to identify aspects that need improvement.

\section{TEST DESCRIPTION}

\section{Facility}

The NTF (Ref. 6-10) is a unique national facility (Figure 1) that enables tests of aircraft configurations at conditions ranging from subsonic to low supersonic speeds at Reynolds numbers up to full-scale flight values, depending on the aircraft type and size. The facility is a fan-driven, closedcircuit, continuous-flow, pressurized wind tunnel capable of operating in either dry air at warm temperatures or nitrogen from warm to cryogenic temperatures.

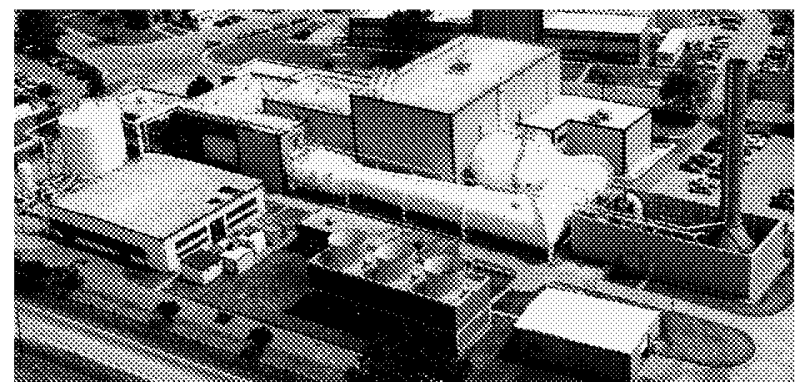

Figure 1. External view of the NTF

For this test program, the tunnel cooling coils used to absorb heat energy during air operations were unusable, so all testing, including warm conditions, as done using nitrogen as the testing fluid. The test section is $8.2 \mathrm{ft}$ by $8.2 \mathrm{ft}$ in cross section and $25 \mathrm{ft}$ in length. The test section floor and ceiling are slotted (6 percent open), and the sidewalls are solid. Freestream turbulence is damped by four screens and a 14.95:1 contraction ratio from the settling chamber to the test section. Fan-noise effects are minimized by an acoustic treatment both upstream and downstream of the fan. A detailed assessment of the dynamic flow quality in the NTF is reported in Ref. 6, and reconfirmed with more recent measurements shown in Ref. 7. The NTF is capable of an absolute pressure range from 15 psi to $125 \mathrm{psi}$, a temperature range from $320^{\circ} \mathrm{F}$ to $150^{\circ} \mathrm{F}$, a Mach number range from 0.2 to 1.2 , and a maximum Reynolds number of $146 \times 10^{6}$ per $\mathrm{ft}$ at Mach 1. Typical tests use a temperature range from $-250^{\circ} \mathrm{F}$ to $120^{\circ} \mathrm{F}$. Further facility details can be found in Refs. 8 and 9 .

\section{Model}

The model is a 0.027 scale model of a Boeing 777 200 transport. The model was designed to be suitable for testing at the high pressure, cryogenic conditions in the NTF. The configuration included pylons and nacelles but not the horizontal tail, and the vertical tail was replaced by an upper swept 
strut/sting supporting the model. Figure 2 is a photograph of the model installed in the NTF test section

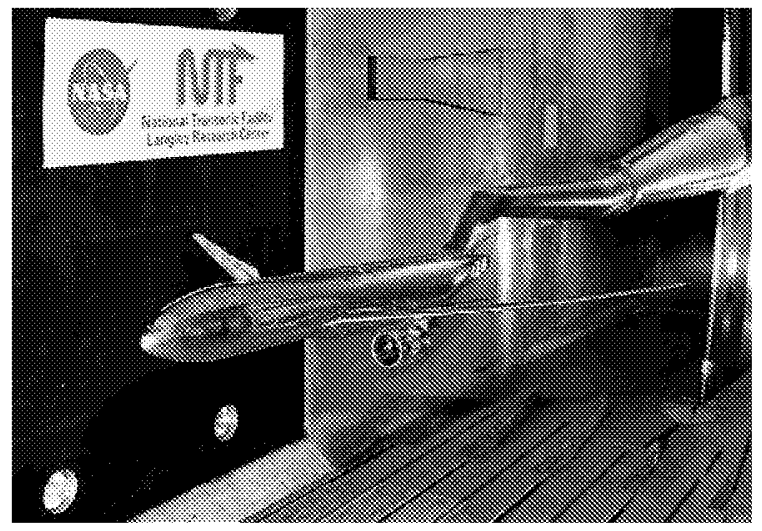

Figure 2. Photograph of model in the NTF

The focus of the wind tunnel test at the NTF was on wing characteristics with the pylon/nacelles installed. Wing vortex generators and flap support fairings were tested on and off to allow comparison with flight data, and CFD.

The maraging steel wings were made in two pieces to eliminate most of the surface cutouts for pressure tube routing, as described in Ref. 4. Filler material was used to cover the remaining orifice tubes on the lower surface. A sketch of the two-piece wing is shown in Figure 3.

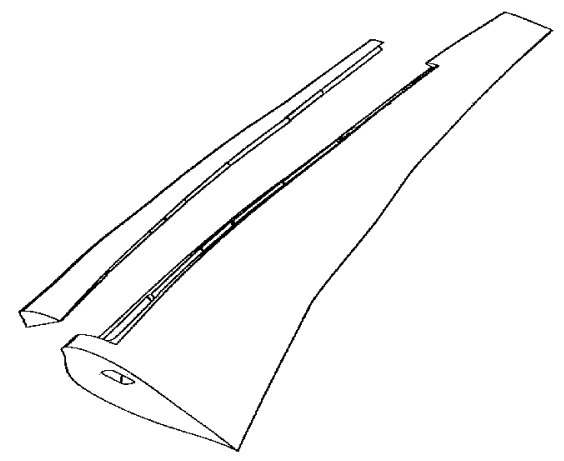

Figure 3. Two-piece wing

Sixteen equally spaced co-rotating rectangular vortex generators (VG's) were placed on the upper surface of each wing. The VG locations represented the production airplane, but the size varied with Reynolds number.

\section{Instrumentation}

Aerodynamic force and moment data were obtained with an internal, unheated, sixcomponent, strain gauge balance. Force and moment data were acquired using the NTF-113D balance, which has maximum component loads shown in Table 1. Because of upper swept strut load limits, side force was limited to $500 \mathrm{lbs}$., but normal force was extended to $7500 \mathrm{lbs}$, with lower limits on pitching moment, to offset the increased normal force limit.

\begin{tabular}{|c|c|c|}
\hline Component & $\begin{array}{c}\text { Full-Scale } \\
\text { Load }\end{array}$ & $\begin{array}{c}\text { Nominal Accuracy } \\
95 \% \text { confidence }\end{array}$ \\
\hline Normal, lbs & \pm 6500 & $\pm 0.09 \%$ full-scale \\
\hline Axial, lbs & \pm 400 & $\pm 0.30 \%$ full-scale \\
\hline Side, lbs & \pm 4000 & $\pm 0.18 \%$ full-scale \\
\hline Pitch, in-lbs & \pm 13000 & $\pm 0.09 \%$ full-scale \\
\hline Yaw, in-lbs & \pm 6500 & $\pm 0.18 \%$ full-scale \\
\hline Roll, in-lbs & \pm 9000 & $\pm 0.29 \%$ full-scale \\
\hline
\end{tabular}

Table 1. NTF-113D balance capacity and accuracy.

A new process for routing instrumentation allowed simultaneous balance and pressure data recording without interference from the ESP package connections in the model nose (Refs. 4, 10). During initial model build-up when the necessary tubing and electrical lines were installed between the nonmetric sting/strut and the ESP package in the model nose, cryogenic cycling was used to detect, correct, and finally verify that no significant restraints were created on the balance output. Using this process required extra model build-up time, but testing in the tunnel was nearly cut in half.

An internal, heated accelerometer package was used to measure the onboard angle-of-attack. Quoted accuracy of the package under smooth operating wind tunnel conditions is \pm 0.01 deg (Ref. 11).

Five 30 psid, and one 45 psid, 64-port ESP transducers were housed in an insulated, heated package in the nose of the model. All the ESP's were used to record pressure data from 9 rows of orifices totaling 283 pressures for the baseline wing. The rows were split about evenly between the left and right wings, so that the wing cutouts could be identical in shape, thus yielding the same flexibility for each wing under load. Six seal pressure orifices located between the nonmetric upper swept strut support and the upper fuselage 
AIAA-2002-0420

were connected to a 5-psid, heated, ESP located in the facility arc sector. Six static pressures inside the left-hand nacelle fan cowl were connected to one of the 30 psid ESP's in the model nose, and were used to calculate internal drag of both nacelles based on calibrations at the Boeing Airflow Calibration Facility.

Wing deformation measurements were made on the top of the fuselage near the centerline, and at five span stations on the wing using a video model deformation system (Ref. 12). The system provided sectional twist change data relative to the wind off shape with a quoted accuracy of \pm 0.10 deg.

\section{Test Conditions}

The test operating envelope at the cruise Mach number is presented in Figure 4. Data was obtained over a Mach number range of $0.4-0.94$. Five Reynolds numbers, based on the mean aerodynamic chord (mac) of the basic trapezoid of the wing, were selected for this test: 3 million (equivalent to BTWT full model), 10.3 million (slightly higher than Ames 11' full model), 16 million (Ames 11' half model), 25 million, and 40 million. Figure 4 indicates that Reynolds number sweeps were achieved along constant $q / E$ lines, where $E$ is the modulus of elasticity of the model material, keeping the shape of the model constant while varying the Reynolds number. This was done at two levels of $q / E$. At constant Reynolds number, 10.3 million, two different q-levels were tested in order to measure and isolate aeroelastic effects on the model. The highest Reynolds number of 40 million was determined by sting divergence criteria for this model and the minimum operating temperature used, $-253^{\circ} \mathrm{F}$. The cooling coils that allow air testing at low Reynolds number broke prior to the test, so all test conditions required cooling with liquid nitrogen. Balance axial and normal force limits as well as model dynamics determined maximum angle of attack obtained, depending on the condition.

The NASA NTF tunnel simulation program (Ref. 13) was used by NASA Langley personnel to help optimize the test plan and fit it in the available tunnel occupancy time and liquid nitrogen (LN2) production and supply. When moisture in the circuit caused the cool-down process to be changed, the simulation results were adjusted to account for additional nitrogen usage.

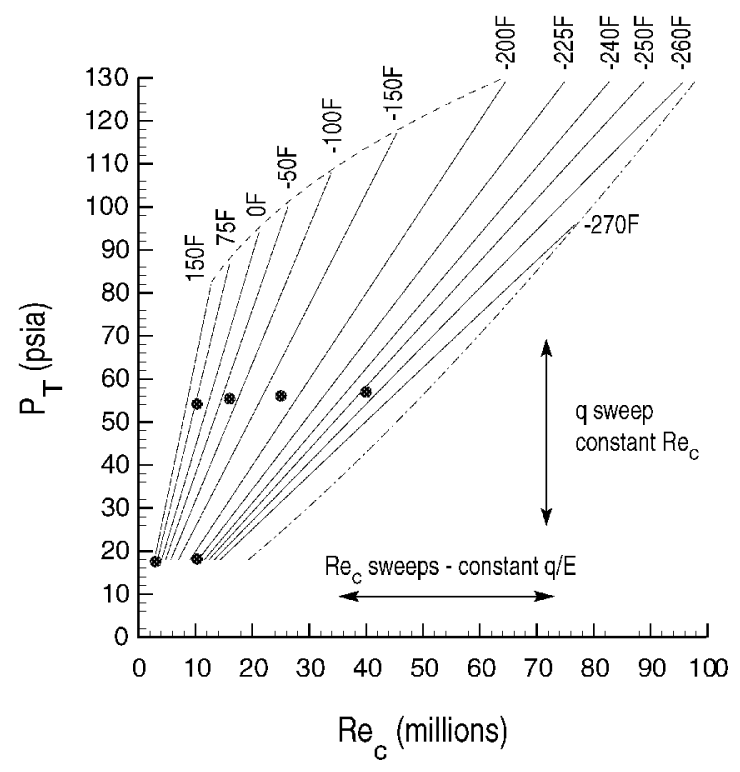

Figure 4. Test operating envelope at cruise Mach

Final data included corrections to angle-of-attack for tunnel upflow, corrections for nacelle internal drag, and corrections for clear tunnel buoyancy. Additional corrections applied were a blockage correction to the tunnel Mach number, and a lift interference correction to angle of attack.

\section{RESULTS}

\section{Comparison Data}

During the development of the 777 , models were tested at the Boeing Transonic Wind Tunnel (BTWT) and NASA Ames 11ft high Reynolds number tunnel. Flight data for the 777 includes force and pressure data taken during the flight test phase of the program. CFD analysis includes results from Tranair (Ref. 14), TLNS3D-MB (Ref. 15) and Overflow (Ref. 16).

\section{Data Quality}

Upflow in the NTF can vary with changes in total pressure, total temperature and model configuration. Therefore, it is necessary to measure upflow at the beginning of a series. This is done by testing short polars with the model inverted and comparing that data to upright data. The variations shown in Figure 5 would create drag variations of \pm 4 counts, which would be unacceptable, if not corrected.

The upflow measured during this test varied by a similar amount compared to recent tests. However to overall level of upflow was lower. 


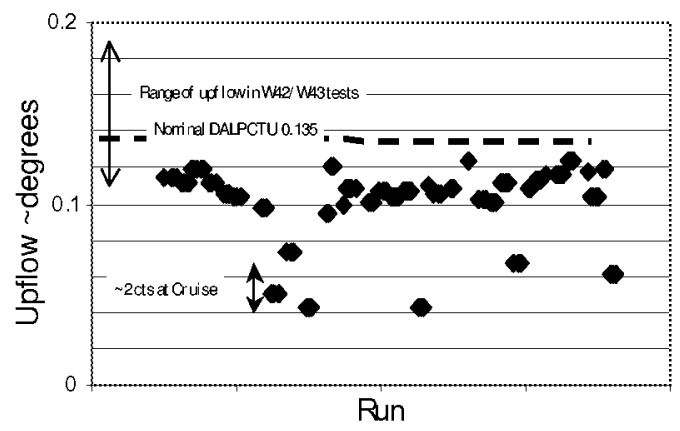

Figure 5. Upflow variation during test

Time and nitrogen budget constraints allow few repeat runs when testing at NTF. Usually, three polars at each Mach=0.7 and cruise Mach are run during a series. Drag standard deviation less than 0.5 count within a series is usually considered quite good repeatability. Standard deviation greater than 1 count within a series makes it difficult to determine drag differences between some configurations. Figure 6 indicates that the standard deviation of $\mathrm{C}_{\mathrm{D}}$ at cruise $\mathrm{C}_{\mathrm{L}}$ for repeat runs within a series is less than 1 count for all configurations and conditions.

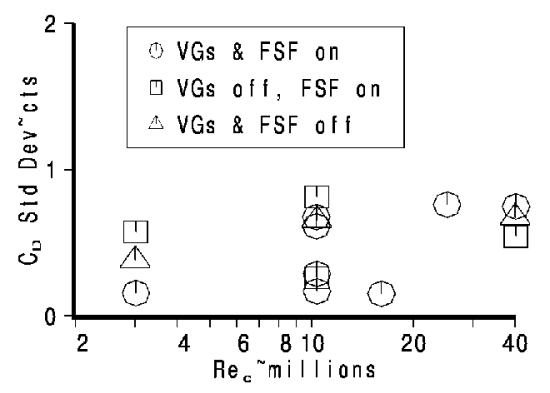

Figure 6. In-series Drag Repeatability at Cruise

Series were repeated at the end of the test for 3 conditions - 40 million Reynolds number, high q and 10.3 million Reynolds number high and low q. For the 10.3 million Reynolds number repeats, the wing trip had been removed and replaced since the first series. The differences between the series averages of the repeated series at cruise Mach and $\mathrm{C}_{L}$ are shown in Table 2.

\begin{tabular}{|c|c|c|}
\hline $\operatorname{Re}_{\mathrm{c}}$ & $\mathrm{q}$ & $\Delta \mathrm{C}_{\mathrm{D}}$ \\
\hline $10.3 \times 10^{6}$ & Low & $0.9 \mathrm{cts}$ \\
\hline $10.3 \times 10^{6}$ & High & $3.8 \mathrm{cts}$ \\
\hline $40 \times 10^{6}$ & High & $0.2 \mathrm{cts}$ \\
\hline
\end{tabular}

Table 2. Between series Drag Repeatability at Cruise

\section{Aeroelastics}

Model aeroelastics must be properly accounted for in order to isolate Reynolds number effects in high pressure tunnels such as the NTF. As the total pressure increases, the Reynolds number and model loads also increase. Higher model loads result in more wash-out for aft swept wings. This decreases the outboard loading, and offsets the general trend for the lift to increase with Reynolds number. Figure 7 shows twist measurements made with the NTF's Video Model Deformation (VMD) system at cruise Mach and $C_{L}$ for 2 different dynamic pressure levels at constant Reynolds number. The difference between these two curves shows that aeroelastic deformation is significant for the NTF model tested.

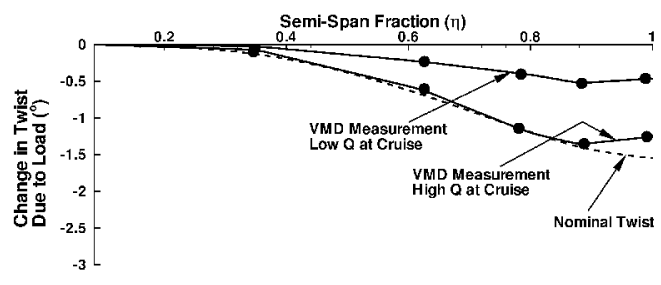

Figure 7. Model twist measurements

The simplest approach to making aeroelastic corrections is to apply an increment between a baseline deformation level and an off design deformation level. Recent high-speed models have been defined and built such that the $1 \mathrm{~g}$ cruise twist is achieved at cruise Mach and angle-ofattack at the highest dynamic pressure tested. Consequently, at the dynamic pressure necessary to obtain 3 million Reynolds number data the wing will not be at the nominal geometric twist. The aeroelastic increment is typically determined by differencing two runs at constant Reynolds number but different dynamic pressures and consequent geometric twist. In this test, increments at 10.3 million Reynolds number are applied to correct 3 million Reynolds number data to the high dynamic pressure level. The incremental method is useful for aeroelastic corrections at a single angle-ofattack, and is generally used for drag measurements.

One shortfall of this method is that even at cruise Mach number, the twist is only correct at one angle-of-attack. Aeroelastic deformation reduces both the lift curve slope and stability levels of the aircraft being tested since the model loads increase and decrease with angle-of-attack even at constant dynamic pressure. Aeroelastic corrections must be applied across the angle-ofattack range in order to determine the Reynolds 
number effect on aerodynamic flight characteristics or external structural loads.

The NTF data presented in this paper have been corrected to constant twist via an experimentally derived sensitivity method. Using the same runs described in the incremental method above, the sensitivity of lift and pitching moment to outboard wing twist was determined using balance data and measured twist. These sensitivities were multiplied by the difference between the outboard twist of a particular run and the nominal $1 \mathrm{~g}$ cruise twist at the same location. Since the sensitivity to twist is assumed linear, the method is not valid in non-linear regions. The corrected data represent a rigid, cruise twist for all angles-of-attack, Mach numbers and dynamic pressures. This removes model aeroelastics from Reynolds number effects.

\section{Flight Performance Prediction For Various RN at NTF}

To predict flight characteristics of the 777 , models were tested at Reynolds numbers from 3 to 16 million and the data was extrapolated to flight $\mathrm{Rn}$ from 42 million and up. Also, the 777 data was compared with 767 wind tunnel and flight data using the same extrapolation methodology to confirm the prediction.

The effect of Reynolds number on drag can be looked at as skin friction and profile drag, polar shape and drag rise. The standard correction from wind tunnel to flight Reynolds number is based on skin friction and profile drag predictions for the configuration. Previous tests (Ref. 4) have indicated that at sub-critical Mach numbers, this method predicts the variation of $\mathrm{C}_{D \text { pmin }}$ with Reynolds number well. However, surface roughness, including that caused by frost, can cause the wind tunnel data to vary from the predicted curve. Figure 8 compares the predicted variation of $\mathrm{C}_{\mathrm{Dpmin}}$ from 3 to 40 million Reynolds number with the NTF data. For this comparison the prediction was for fully turbulent flow and was shifted to match the NTF data at 10.3 million Reynolds number, because at high q that condition was warm enough $\left(63^{\circ} \mathrm{F}\right)$ that frost was not a concern. The data was corrected for laminar flow forward of the $10 \%$ trip at the lower Reynolds numbers and for the trip drag. The higher Reynolds numbers (25 and 40 million) were assumed to be fully turbulent and had no trip on the wing.

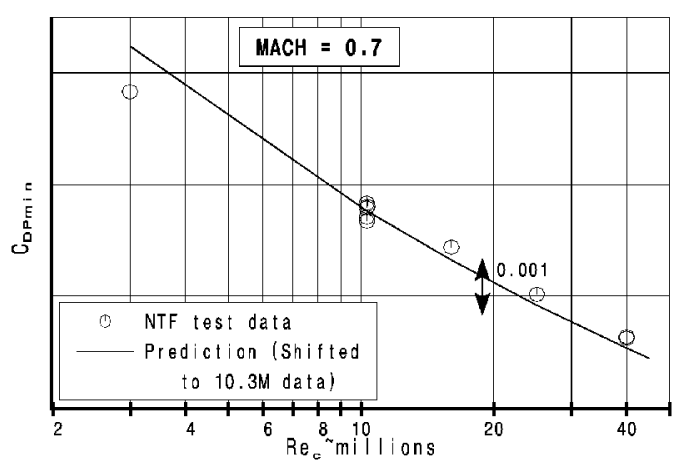

Figure 8. Reynolds number effect on drag at Mach $=0.7$

The NTF data follow nearly the same trend in $\mathrm{C}_{\text {Dpmin }}$ vs. Reynolds number compared to the prediction. There were several repeated conditions and configurations at 10.3 million Reynolds number, including re-application of the trip. The drag variation is noticeable.

Beyond the skin friction and profile drag correction, the changes in polar shape and Mach effects between low and high Reynolds number are of particular interest in this testing. In the past, no adjustment to these characteristics has been made above the highest Reynolds number tested in the wind tunnel.

In Figure 9 the drag polars have been shifted to $\mathrm{C}_{\text {Dpmin }}=0$ to show the effect of Reynolds number on polar shape for both the vortex generators on and off configurations. The polar shape shows a dependence on Reynolds number. However, the Reynolds number effect appears to be slightly reduced with the vortex generators on.

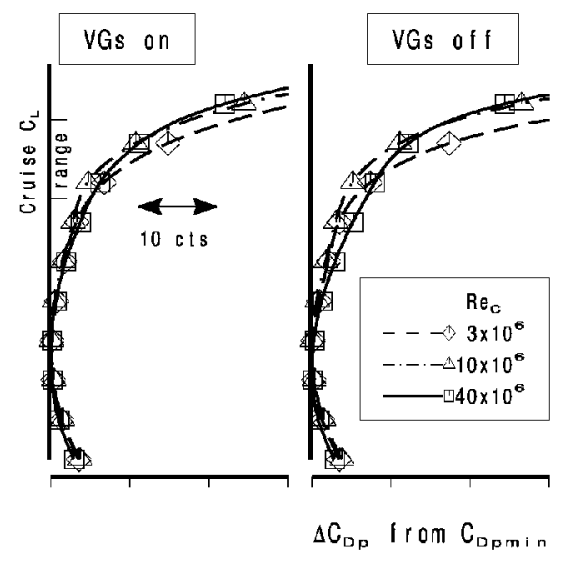

Figure 9. Polar shape variation with Reynolds number at cruise Mach 
The variations of drag with Reynolds number predicted by several CFD codes were compared to the NTF results with flap support fairings and vortex generators off. All of the CFD analyses included turbulent boundary layer on the wing, body and nacelle. Figure 10 shows the total drag predicted by various codes at cruise Mach and $\mathrm{C}_{\mathrm{L}}$ compared to NTF and pre-flight Ames $11 \mathrm{ft}$ test data.

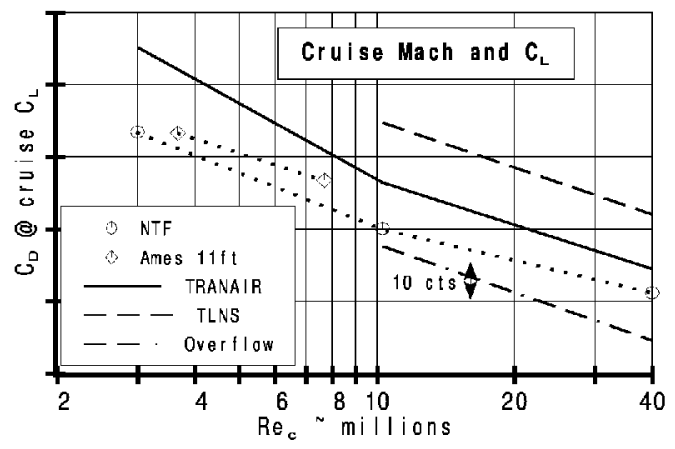

Figure 10. Drag variation with Reynolds number at cruise

Two TLNS3D-MB cases were run for each Reynolds number - with the trailing edge closed and with it blunt, representing the model. The Tranair and Overflow models had closed trailing edges. The drag difference between these cases is not notable at the scale of this plot. Tranair and TLNS3D-MB drag results are higher than the NTF data and Overflow results are lower. The drag variation with Reynolds number predicted by the CFD codes does not match the NTF data.

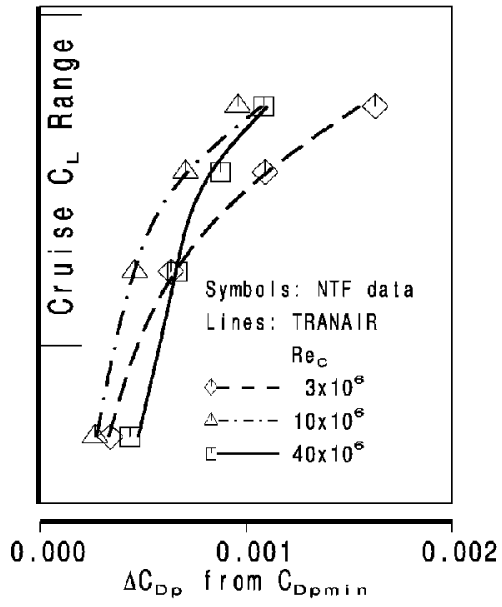

Figure 11. Tranair vs NTF polar shapes at cruise Mach

The Tranair polar shape results in the cruise $\mathrm{C}_{\mathrm{L}}$ range are more promising. In Figure 11 the Tranair results (lines) were shifted in drag to match the NTF data (symbols) at the middle of the cruise $C_{L}$ range for each Reynolds number. Tranair predicts the changes in polar shape between Reynolds numbers well. However the discrepancy in level and trend with Reynolds number indicates that the profile and skin friction drag components need to be better understood for all CFD codes.

Figure 12 shows that the drag rise from Mach $=0.7$ is lower at higher Reynolds numbers. This indicates that higher Reynolds number testing would predict a slightly higher cruise Mach number.

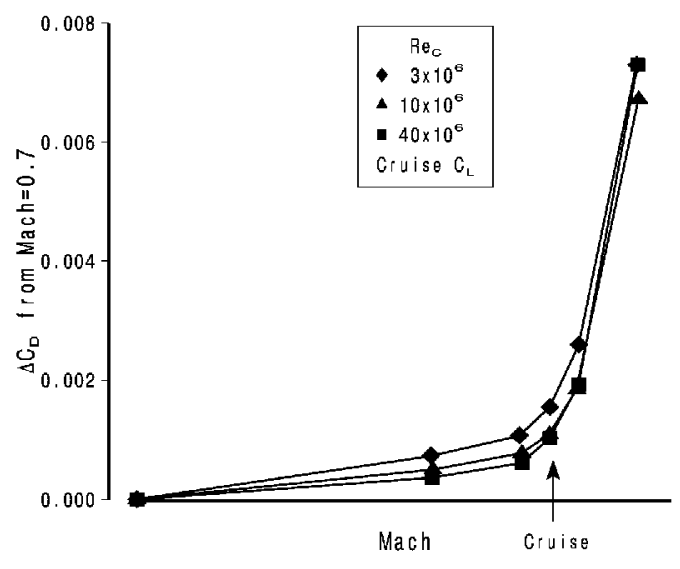

Figure 12. Effect of Reynolds number on drag rise

The wing-to-body incidence is influenced by limits on maximum body incidence during cruise. This requirement can limit the flexibility in optimizing wing-to-body incidence. Figure 13 shows that the incidence at cruise $C_{L}$ and Mach continues to change above the highest Reynolds number tested before the 777 was built. The flight test incidence, shown corrected for estimated tail and trim is close to the highest Reynolds number NTF data.

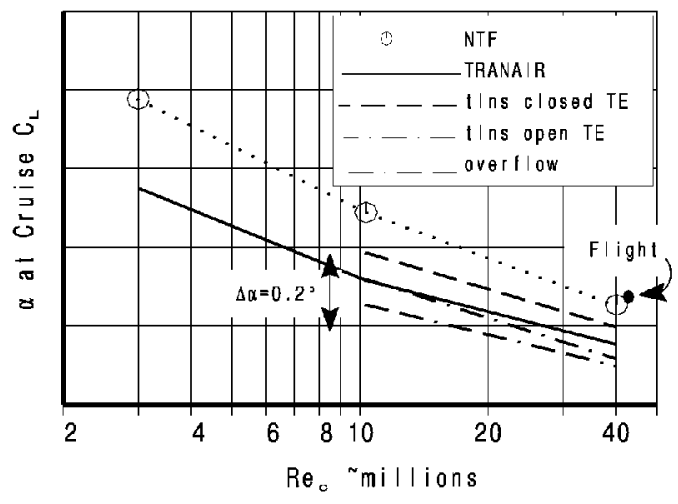

Figure 13. Effect of Reynolds number on $\alpha$ at cruise 
The incidence at cruise $C_{L}$ predicted by CFD is lower for all codes at all Reynolds numbers than the NTF data. The trend of incidence with Reynolds number is closest to NTF data for the TLNS3D-MB results with a blunt trailing edge.

Although the data were gathered tail-off, the Reynolds number trends are still useful for flight characteristics scaling. Of prime concern is what effect Reynolds number has on high angle-ofattack longitudinal characteristics, as well as linear range characteristics such as pitch stability and lift and pitching moment levels at constant angle-ofattack.
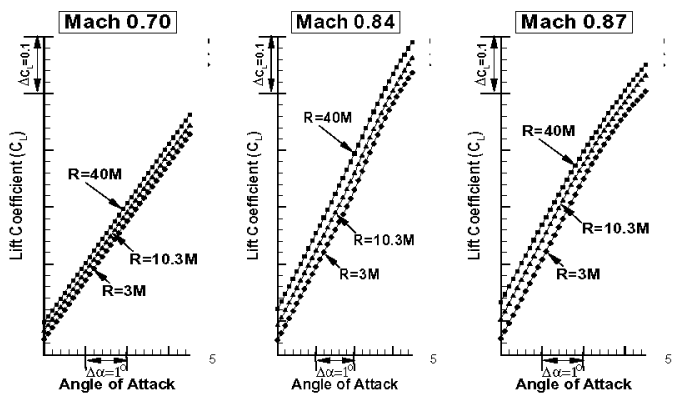

Figure 14. Reynolds number effect on lift curves

Lift curves are presented in Figure 14 below for 3 Mach numbers and 3 Reynolds numbers. The principal effect of Reynolds number on these curves is to increase the lift across the angle-ofattack range progressively from 3 to 40 million Reynolds number. The lift curve slope does not vary significantly from low to high Reynolds number conditions.

Pitching moment curves are shown in Figure 15 for a variety of Reynolds numbers at Mach 0.84 . NTF results shown in the solid lines indicate a significant nose down trend with increasing Reynolds number. Dashed lines show results extracted from flight test and relatively low Reynolds number data from BTWT.

The pitching moment offset between the BTWT/Flight data and the NTF data is most likely due to mounting system interference. The BTWT data have been corrected for mounting system interference, while the NTF data have not. A future NTF test is planned to quantify mounting system effects. Comparisons of the curves reveal two significant results. First, the shape of the curves at 3 and 40 million Reynolds number agrees relatively well with BTWT and flight data respectively. Second, the NTF data predicts the nose down pitching moment shift reasonably well compared with BTWT to flight trends. Tail-off pitch stability may be determined by the inverse of the slope of the curves in Figure 15 divided by the local lift curve slope. The NTF data clearly show a stability increase from 3 to 40 million Reynolds number. These results are consistent with data presented in Ref. 4.

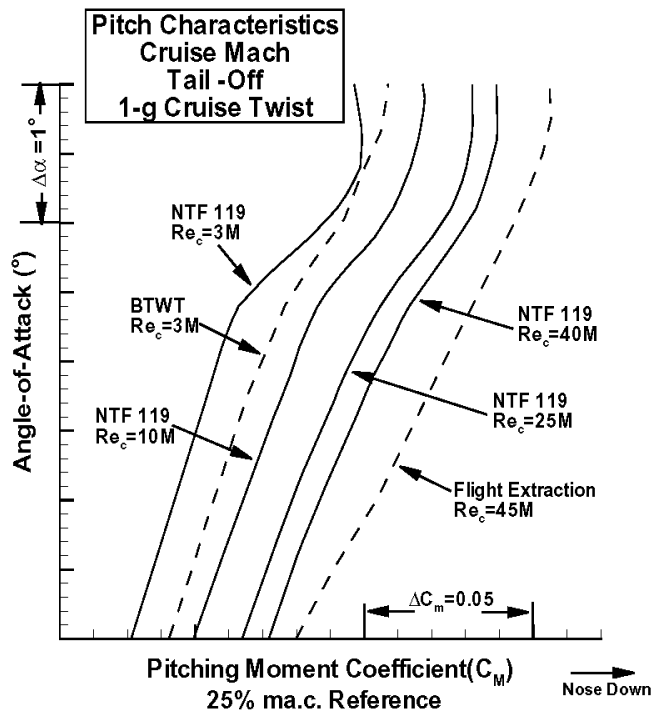

Figure 15. Effect of Reynolds number on Pitching moment curves

Figures 16 and 17 show the change in lift at constant angle-of-attack from a variety of data sources. Data in Figure 15 differ from the alpha plots shown previously in Figure 13 by the local lift curve slope. The data show lift progressively increases and the pitching moment becomes progressively nose down as the Reynolds number increases from 3 to 40 million. Lift values extracted from flight test and data from the Boeing Transonic Wind Tunnel (BTWT) are shown in both figures. The change in lift due to Reynolds number from the NTF matches the BTWT to flight increment relatively well. The magnitudes are shown to be significant, amounting to roughly $0.5^{\circ}$ of angle-of-attack and a change in pitching moment equivalent to roughly $0.75^{\circ}$ of stabilizer incidence. It should be noted that tail-on pitching moment Reynolds number effects will be smaller than tail-off trends shown since the increase in wing downwash due to Reynolds number will partially offset the tail-off trends. Vortex generators are shown to have less effect on lift at higher Reynolds number than at lower Reynolds numbers. 


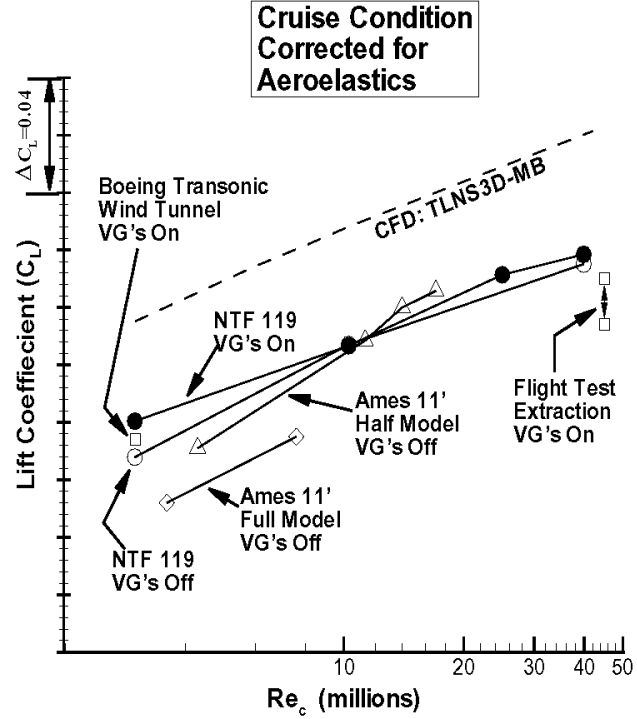

Figure 16. Effect of Reynolds number on Lift at cruise conditions

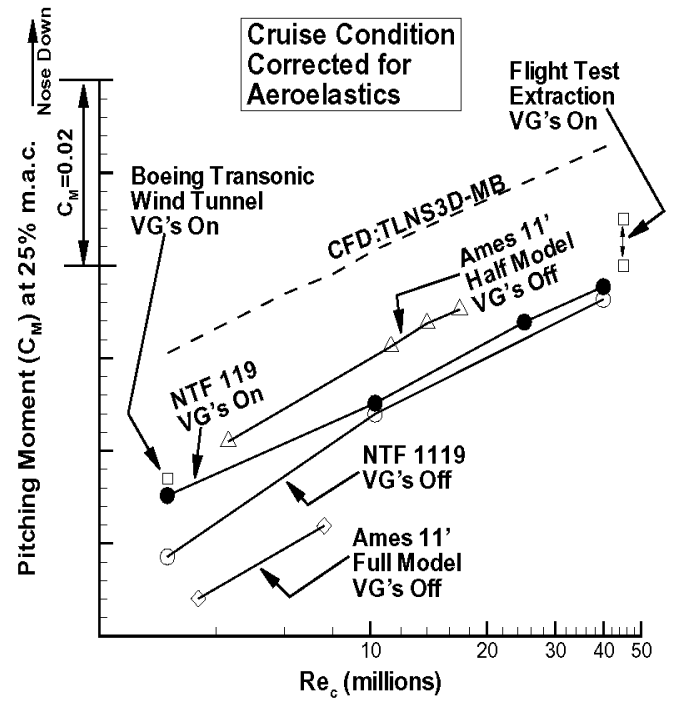

Figure 17. Effect of Reynolds number on Pitching moment at cruise conditions

Reynolds number trends from the Ames 11' transonic wind tunnel are also shown, and the lift and pitching moment trends for both half and full model configurations are similar to the NTF trends. Prior to flight test, it was not known if the lift or pitching moment trends would continue to increase beyond the 16 million Reynolds number tested in the Ames 11' wind tunnel to flight Reynolds number. While it is likely that the trends asymptote at some Reynolds number, the results indicate that they do not asymptote before 40 million Reynolds number. CFD results from the Navier-Stokes code TLNS3D-MB are also presented. The correlation shows a significant shift in lift and pitching moment between the CFD and wind tunnel data. Reynolds number trends correlate much better, and TLNS3D-MB predicts the changes in lift and pitching moment between 10 and 40 million quite well, and the change between 3 and 10 million relatively well. This suggests that Navier-Stokes methods may be employed to scale linear range trends from around 10 million Reynolds number to flight levels on generic transport configurations.

\section{Vortex Generator Effects on Draq}

Figure 18 shows the VG drag increment at cruise conditions for three Reynolds numbers. The VG's have a small, favorable effect on polar shape, so that the drag increment is smaller at higher $\mathrm{C}_{\llcorner}$. The VG's are scaled to account for predicted boundary layer thickness, so have larger drag at lower Reynolds numbers. At 40 million Reynolds number the drag increment at cruise is negligible or slightly favorable.

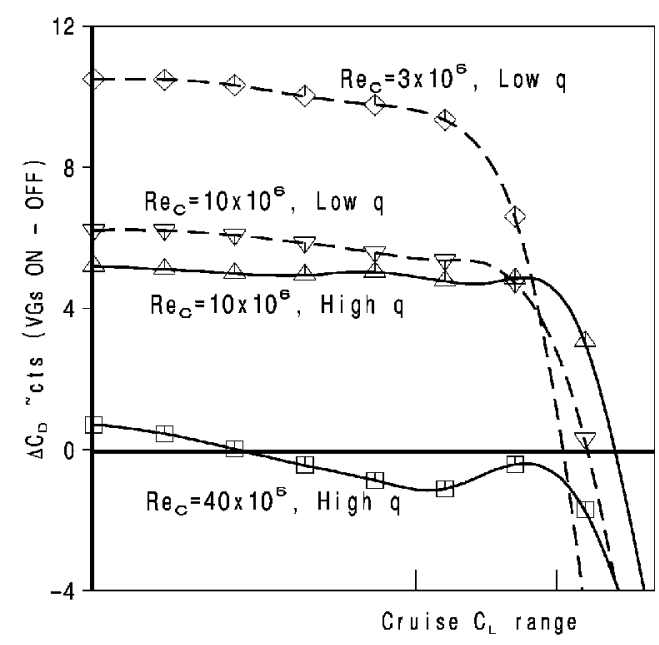

Figure 18. VG effect on drag at cruise Mach

\section{Pressure Characteristics}

Figure 19 shows aftloading continues to increase with Reynolds number for VG's on. This data is cruise Mach number and $\mathrm{C}_{\mathrm{L}}$ at a mid-board pressure row. Aftloading is approximated by the difference between lower and upper surface pressures at $85 \%$ chord. Higher aftloading generally indicates less negative rooftop $\mathrm{C}_{P}$ and lower shock strengths, providing less drag. However, it can require higher structural weight for flap and aileron support. 
The aftloading measured in flight test is shown in Figure 19 for comparison. The aftloading at 40 million Reynolds number from the NTF test is close to the flight test data.

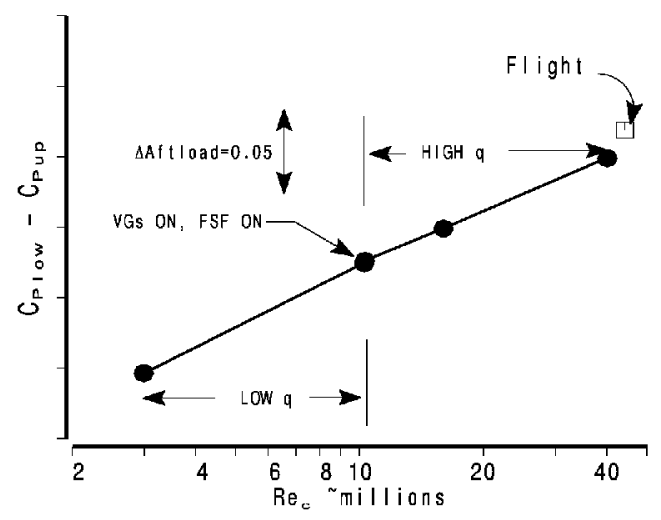

Figure 19. Aftloading variation with Reynolds number at cruise conditions

Figure 20 compares aftloading predicted by CFD to wind tunnel data for the flap support fairing and VG's off at cruise Mach \& $C_{L}$. All CFD results indicate higher aftloading than test data at low Reynolds number. None of the CFD results match the trend of the NTF data, but TLNS3D-MB results are closer than Tranair. TLNS3D-MB results indicate that the blunt trailing edge increases aft load relative to closed, but the trend with Reynolds number doesn't change.

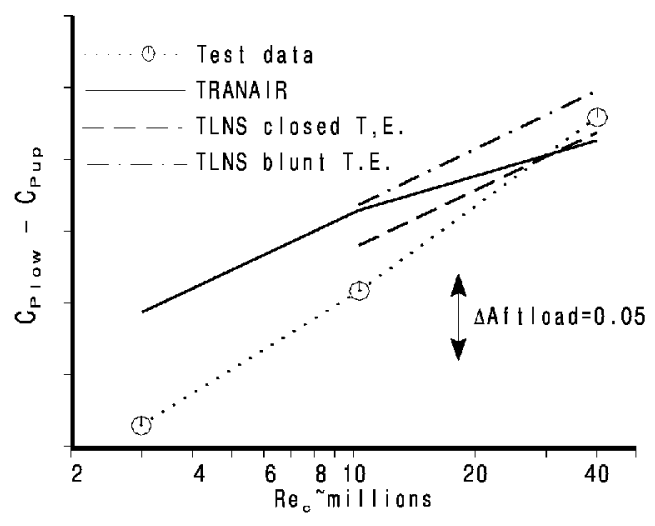

Figure 20. CFD prediction of aftloading at cruise conditions

Figure 21 indicates trailing edge separation at one of the mid-board pressure rows by tracking the pressure at $95 \%$ chord, since there was no port at the trailing edge. Separation is indicated when the $\mathrm{C}_{\mathrm{P}}$ suddenly becomes more negative. The test data, shown as lines, indicate that separation occurs at a higher $\mathrm{C}_{\llcorner}$at higher Reynolds numbers. Overflow results for $4 \mathrm{C}_{\llcorner}$'s are shown as symbols. At lower $\mathrm{C}_{\mathrm{L}}$, where the flow is attached, the overflow results show more positive $C_{p}$ at 40 million Reynolds number, but in the test data $\mathrm{C}_{p}$ is more negative at higher Reynolds number, prior to separation. The overflow cases are not at high enough $C_{L}$ to clearly indicate separation.

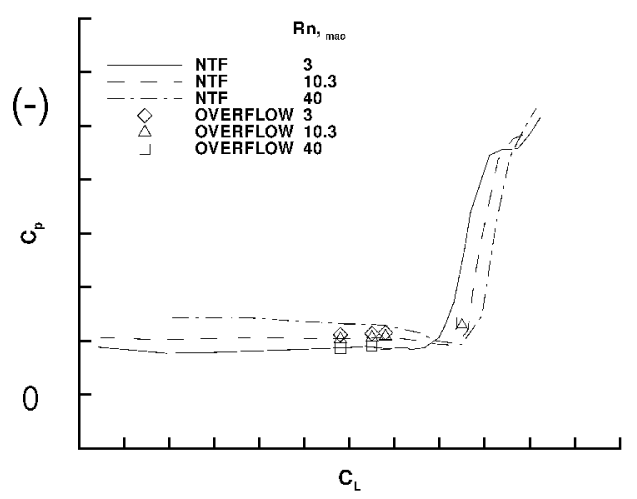

Figure 21. Reynolds number effect on trailing edge separation $(x / c=95 \%)$ for VG's off

Figure 22 shows the change in $C_{p}$ at $95 \%$ chord due to VG's (VG's on - VG's off). The positive $C_{p}$ increment indicates the VG's delay separation. The separation is delayed slightly more for higher Reynolds number.

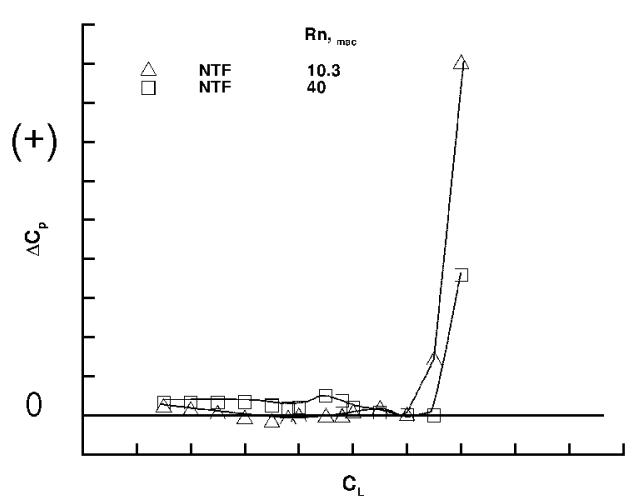

Figure 22. Change in trailing edge separation $(x / c=95 \%)$ due to VG's (on - off)

\section{ISSUES}

Ref. 4 describes issues that were encountered in testing commercial transport configurations at NTF. Many of these issues were present during this test. The issues that had the most significant 
AIAA-2002-0420

impact on test operations were simultaneous measurement of pressure and drag, moisture contamination and the liquid nitrogen supply.

\section{Simultaneous Measurement of Pressure and Drag}

Previous tests in the NTF have been split into two parts. After pressure data was obtained, the lines were removed from the model for drag testing because the pressure instrumentation interfered with axial force measurements (Ref. 17). This resulted in very long tests. In 1999 a test in NTF (Ref. 10) with a calibration model with new routing methods for the pressure data lines demonstrated that this methodology produces reliable drag data while obtaining pressure data.

The ability to simultaneously acquire drag and pressure data significantly increased the tunnel productivity.

\section{Moisture Contamination}

A constant concern when wind tunnel testing in a cryogenic environment is the potential for moisture contamination (Ref. 18). Frost can accumulate on the model at cryogenic conditions at levels of moisture that would be considered very dry in ordinary circumstances.

Moisture contamination became a major issue in this test. Before the test, the cooling coils used for running in air at low Reynolds number broke, spilling water into the circuit. This got into the insulation and became hard to remove. Attempts to achieve cold conditions early in the test were confounded by frost on the model. The test was stopped to dry out the circuit, but moisture remained a problem throughout the test.

The testing staff developed processes to minimize moisture content and prevent frost. Although these were successful, they resulted in a large test time and nitrogen drain. Pre-test predictions were considerably less than actual N2 use because of additional time spent purging the circuit of moisture. The usual procedure is to run the tunnel until the visible frost has sublimated. However, it was not uncommon that the tunnel had to be purged to remove frost from model.

Despite the operational problems caused by the moisture, we believe the data to be good, thanks to the vigilance of the entire test crew.

After this test was complete, work was done at NTF to reduce the impact of moisture on operations.

\section{Liquid Nitrogen Supply}

The NTF uses nitrogen as a test gas for most operations. Liquid nitrogen is produced in a facility near the wind tunnel and stored in tanks adjacent to the tunnel and at the nitrogen production facility. The total storage capacity is 6400 tons, including 3700 tons at NTF and 2700 tons at the production facility. At a maximum production rate of 300 tons/day it takes 3 weeks to fill the tanks once empty. High Reynolds number, high pressure, cryogenic testing empties the tanks in 1-2 weeks, even though nitrogen is being produced while testing.

Test planning is usually arranged so that testing in air can use some of the time while waiting for the nitrogen tanks to fill. However, there are a limited number of conditions available in air. Also, during this test the air mode was not available. This resulted in long waiting periods between short testing periods.

A more continuous supply of nitrogen during testing, or an expanded Reynolds number capability in air would increase the usefulness of the NTF. Since down times between tests can be long, it's not reasonable to expect a facility that can produce nitrogen at the same rate it is used. However, some additional production capacity, additional storage or capability to deliver nitrogen by truck would reduce downtime waiting for nitrogen.

\section{CONCLUDING REMARKS}

Transonic testing conducted in the NTF has advanced the understanding of Reynolds number scaling for subsonic airplanes. Several issues as outlined in the "Issues Section" of this paper and Ref. 4 need to be aggressively worked in order to increase the usefulness of the facility.

Besides identifying Reynolds number scaling effects, this test data will provide comparisons to improve CFD prediction. There is a continuing effort to model a range of conditions using several CFD codes for comparison.

Tail-on and tare-and-interference testing is planned for the near future. This will improve our understanding of wind tunnel to flight prediction.

Based on the results presented in this paper, it can be concluded that data obtained at low Reynolds number can be misleading for airplane designers if not corrected for Reynolds number effects. Significant conclusions drawn from this study are as follows: 
1. New processes for instrumentation routing allowed simultaneous measurement of pressure and drag, saving a considerable amount of time and nitrogen.

2. The most significant dependency on Reynolds number for drag polar shape and drag rise occurs between 3 and 10.3 million.

3. Linear range lift and pitching moment Reynolds number effects increase roughly linearly between 3 and 40 million Reynolds number, and agree with flight data relatively well.

4. VG's have little measurable drag impact at cruise flight conditions.

5. Video Model Deformation data provided a useful and accurate means of correcting for aeroelastic deformation across the angle-ofattack range.

6. CFD shows promise for predicting scale effect trends for lift and pitching moment, but there are discrepancies in levels for all parameters and in trend for drag between CFD and wind tunnel data.

\section{ACKNOWLEDGEMENTS}

The NTF test and joint analysis were conducted under NASA LaRC/Boeing Space Act Agreement \#469. The support of program managers Joan Funk of NASA LaRC and Doug Ball of Boeing is greatly appreciated. The authors would also like to thank the entire staff at the NTF, most notably lead test engineer Bill Tomek, for their efforts. Finally, the assistance of the following people in model design, test preparation, test support, data reduction and analysis is also greatly appreciated: Susan Palmer, Bill Kimmel, Charlie Davidson, David Lewis, and Julie Pollitt of NASA; and Jan Barani, Dale Belter, Fritz Brendemihl, Tom Butler, Bill Carver, Allen Chen, Wayne Davidson, Jeff Harrigan, Pei Li, Steve Mysko, Tim Purcell, Allison Proctor, Karel Schippers, Chris Vegter, Vinh Tat, and Dave Witkowski of Boeing.

\section{REFERENCES}

1. Goldhammer, M. I. and Steinle, F. W., Jr., "Design and Validation of Advanced Transonic Wings Using CFD and Very High Reynolds Number Wind Tunnel Testing," $17^{\text {th }}$ ICAS Congress, September 1990.
2. Wahls, R. A., Gloss, B. B., Flechner, S. G., Johnson, W. G., Jr., Wright, F. L., Nelson, C. P., Nelson, R. S., Elzey, M. $\theta$ B., and Hergert, D. W., "A High Reynolds Number Investigation of a Commercial Transport Model in the National Transonic Facility," NASA TM-4418, April 1993.

3. Wahls, R. A., Adcock, J. B., Witkowski, D. P. and Wright, F. L., "A Longitudinal Aerodynamic Data Repeatability Study for a Commercial Transport Model in the National Transonic Facility," NASA TP-3522, August 1995.

4. Om, D., Curtin, M. M., Bogue, D. R., Witkowski, D. P., and Ball, D. N., "Reynolds Number Effects on a Subsonic Transport at Transonic Conditions," AIAA Paper 20010909, January 2001.

5. Al-Saadi, J. A., "Effect of Reynolds Number, Boundary-Layer Transition, and Aeroelasticity on Longitudinal Aerodynamic Characteristics of a Subsonic Transport Wing," NASA TP3655, September 1997.

6. Igoe, W. B., "Analysis of Fluctuating Static Pressure Measurements in the National Transonic Facility," NASA TP-3475, March 1996.

7. Bobbitt, C. W., Hemsch, M. J. and Everhart, J. L., "NTF Characterization Status," AIAA Paper 2001-755, January 2001.

8. Fuller, D. E., "Guide for Users of the National Transonic Facility," NASA TM-83124, 1981.

9. Foster, J. M. and Adcock, J. B., "User's Guide for the National Transonic Facility Research Data System," NASA TM-110242, April 1996.

10. Kilgore, W. A., Balakriskna, S., Bobbitt, C. W., Jr. and Adcock, J. B., "Recent National Transonic Facility Test Process Improvements," AIAA-2001-0756, January, 2001

11. Finley, T. D. and Tcheng, P., "Model Attitude Measurements at NASA Langley Research Center," AIAA Paper 92-0763, 1992.

12. Burner, A. W., and Martinson, S. D., "Automated Wing Twist and Bending Measurements under Aerodynamic Load," AIAA Paper 96-2253, June 1996.

13. Mineck, R. E., Owens, L. R., Wahls, R. A., and Hannon, J. A., "Computer model to simulate Testing at the National Transonic Facility," NASA TM 4664, August 1995. 
14. Smith, M. W., "Ease of Use for Tranair Analysis Problems," SAE World Aeronautical Conference, September, 1998.

15. Vatsa, V. N., Sanetrik, M. D. and Parlette, E. B., "Development of a Flexible and Efficient Multigrid-Based Multiblock Flow Solver," AIAA paper 93-0677, January, 1993.

16. Jespersen, D. C., Pulliam, T. H. and Buning, P. G., "Recent Enhancements to Overflow," AIAA-97-0644, AIAA 35th Aerospace Sciences Meeting, Reno, NV, Jan. 1997.

17. Mineck, R. E. and Pendergraft, O. C.,Jr.: "Test-to-Test Repeatability of Results From a Subsonic Wing-Body Configuration in the National Transonic Facility", NASA TM-2000210079, March 2000.

18. Gloss, B., and Bruce, R., "A Solution to Water Vapor in the National Transonic Facility," AIAA Paper 89-0152, January 1989. 